\title{
PERSPECTIVAS LINGUÍSTICAS: DIVERGENTES OU COMPLEMENTARES?
}

\author{
Diognes Ramos Marchon (UERJ e PUC-RJ) \\ diognesmarchon@yahoo.com.br
}

\section{Por onde começar?}

O estudo de Gramática tem sido altamente requisitado nas diversas modalidades pedagógicas e preparatórias de conteúdos programáticos, pois é sabido que o domínio das suas terminologias e de seus conceitos constitui, para os dias atuais, uma importante "habilidade a ser adquirida". No entanto, a compreensão de importância da gramática tem ocupado um lugar de destaque no estudo da língua, chegando até uma ser entendida como sinônimo da outra.

Por sua vez, a Linguística, destinada ao estudo científico das línguas naturais, é vista como uma disciplina estritamente acadêmica, importante para a formação docente, porém com pouca ou nenhuma aplicabilidade aparente em sala de aula. Por outro lado, o professor que deseja fazer uma abordagem mais embasada das normas gramaticais da língua portuguesa, por exemplo, talvez recorra aos conteúdos da Linguística por entender que, em alguns momentos, eles são necessários para um ensino de propriedade e para a resolução de incompatibilidades deparadas nas gramáticas normativas.

Ao se atribuir a devida atenção à Linguística para o ensino, em paralelo com a grande quantidade de gramáticas da norma, o pesquisador provavelmente deparar-se-á com algumas contradições destas últimas, principalmente em relação à grande oscilação entre critérios semânticos, sintáticos e morfológicos na abordagem de definições gramaticais, provocando, assim, uma enorme imprecisão nos respectivos conceitos. Todavia, quando se recorre a teóricos linguísticos, percebe-se que muitas das dúvidas inicialmente surgidas são direcionadas a outras discussões mais profundas, revelando perspectivas distintas para se observar um mesmo objeto, provocando, assim, uma ligeira sensação de que não vai se chegar à conclusão alguma. 
Entretanto, as diferenças de pontos de vista nos estudos linguísticos não devem ser encaradas como uma frustração àquele que inicia um estudo científico da língua; pelo contrário, é uma excelente oportunidade em observar, por diferentes aspectos, o fenômeno linguístico. A Linguística, além de estabelecer a língua como objeto científico de estudo, também agrega discussões avançadas e inúmeras respostas para perguntas não pouco elementares, oferecendo, inclusive, consideráveis contribuições para o ensino. Mas é fato que na Linguística diversas correntes versam opiniões distintas para um mesmo item até, relativizando em muito as precisões impostas pelos gramáticos normativos ou por qualquer que ouse oferecer uma proposta mais certa que as outras.

O objetivo do presente texto é abordar o principal embate figurado na Linguística moderna, a saber, entre o Polo Formalista (PFO) e o Polo Funcionalista (PFU), bem como demais movimentos que se entendem ser agregados a esses dois importantes parâmetros. Também serão observadas as contribuições da Sociolinguística e sua posição ante aos dois primeiros, compondo, desta forma, o quadro geral das ciências que vigoram neste início de século.

\section{Uma longa história}

A abordagem sobre o caráter científico da Linguística constitui um dos importantes pontos de partida para se estudar e entender os diversos quadros teóricos linguísticos existentes. A aparente simplicidade na definição da Linguística como "ciência das línguas naturais" pode levar à desconsideração de toda uma história de intensas discussões que se debruçaram sobre o estudo da linguagem, que moveram por um longo ou por um curto espaço de tempo sua concepção de objeto de estudo. Cada movimento teórico era ou é, em parte, uma reação a um movimento vigente ou antecedente, de modo que é importante observá-las panoramicamente, uma vez que, de alguma forma, os parâmetros teóricos estão intrinsecamente relacionados. Vale ressaltar que, muitas vezes, cada teoria da linguagem está respaldada em um pensamento que não influenciou apenas um determinado estudo linguístico, mas toda uma geração. 


\subsection{Gramática tradicional}

A maioria das gramáticas de língua portuguesa tem na palavra o primeiro passo de análise da língua. É através dela que se fazem as explicações sobre o surgimento do português, quando as palavras passaram a fazer parte do patrimônio lexical do idioma. Do ponto de vista histórico, os vocábulos se originaram do latim, através de um longo processo de transformações que culminou no que se considera o acervo atual do nosso vocabulário.

O estudo da língua, a partir da observação das palavras, se desdobra em dois módulos componentes: léxico e gramático. No módulo lexical, é largamente utilizado o critério nocional, em que se busca elucidar a referência direta da palavra na representação do pensamento, ou seja, o seu significado. Já no aspecto gramatical, as palavras são analisadas de acordo com parâmetros morfológicos pois possuem uma estrutura e uma formação que requerem uma classificação - e sintáticos - pois intermedeiam as relações sintagmáticas da frase. Seguindo tais critérios, as palavras da língua portuguesa são organizadas em dez classes gramaticais.

A aplicação para a relação das classes de palavras da língua portuguesa segue o padrão da gramática latina, que por sua vez se baseou fortemente na gramática grega. E não é para tanto: a análise gramatical surgiu ainda na antiguidade clássica grega, até fins do século XIX, concentrada no conceito de vocábulo. Desenvolveu-se, nesse período, o movimento de estudo da linguagem denominado Gramática Tradicional.

O empenho dos filósofos na formulação precisa das gramáticas tradicionais atendia a objetivos claros: reunir e sistematizar os meios de estruturação das unidades significativas da língua. O papel primordial da linguagem, defendida pelos teóricos do racionalismo, seria a de cumprir a função instrumental de representar os conceitos idiossincráticos (proposição) e corresponder, sem prejuízos de expressão, à estrutura do pensamento (raciocínio). Para tanto, o trabalho de pesquisa aos textos clássicos (docência) era primordial para que a essência da língua, encontrada nos poetas do passado, fosse preservada das corrupções e anomalias. 
O movimento em questão atingiu seu auge nos séculos XVII e XVIII, com os trabalhos dos gramáticos racionalistas de Port-Royal; esses teóricos buscavam apoiar as línguas vernáculas nos mesmos fundamentos das gramáticas eruditas latinas e filosóficas gregas. Consequentemente, desenvolveu-se a tese do universalismo, a ideia de que todas as línguas compartilhavam dos mesmos princípios linguísticos, de natureza mental. De certa forma, as gramáticas lógicas influenciaram profundamente o modelo de análise sintática que se pratica até hoje nas escolas.

\subsection{Os neogramáticos e o historicismo}

Em meados do século XIX, o historicismo pôs em xeque a tradicional visão racionalista de mundo e de linguagem. Para esta corrente de pensamento, as configurações contemporâneas do mundo humano não são frutos de uma conclusão intuitiva ou reflexiva, mas o resultado de processos históricos dos códigos sociais, observados a partir de um método de investigação e de reconstrução dos fatos causadores. Sendo assim, a linguagem não poderia ser nada mais além do que o resultado da inspiração e das transformações culturais ocorridas durante o tempo e buscar essa origem era o mesmo que descobrir a identidade de um povo. Esta concepção de linguagem moveu os neogramáticos na pesquisa das transformações que deram origem às línguas, bem como conhecer a origem e as particularidades de cada uma.

A condição científica de um estudo da linguagem consistiria para os neogramáticos exatamente no seu caráter historicista. Enquanto para os estudiosos racionalistas as línguas seriam construtos mentais, cujas entidades de pensamento seriam a essência de sua estrutura, para os neogramáticos "as línguas são o que são porque, no decorrer do tempo, elas estiveram sujeitas a uma variedade de forças causativas internas" (LYONS, 1987). Para tanto, a única explicação válida para a linguística seria a historicista, cujo método de análise deixaria de ser meramente especulativo (opondo-se totalmente à gramática tradicional), passando a ser objetivo.

O método mais difundido, portanto, foi o histórico-comparativo, cujo princípio seria a de elucidar verdadeiramente as causas que 
influenciaram as unidades das línguas, buscando estabelecer a universalidade, a continuidade e a regularidade das transformações de diversas naturezas.

Além do historicismo, a "questão da língua" também ocupou considerável parte dos estudos sobre a linguagem, inclusive para o ensino pedagógico. Desta forma, utilizando as palavras de Azeredo, "o estudo das línguas assumia, assim, duas modalidades: uma, histórica e crítica, ostentando o prestígio de ciência; outra, descritiva e prática, assumindo a 'modéstia' de sua finalidade utilitária" (AZEREDO, 2003).

\subsection{O pioneirismo de Saussure}

A geração dos neogramáticos empregou uma forte tendência para o método histórico-comparativo das línguas. A perspectiva diacrônica atribuiu aos estudos linguísticos um princípio historicista que, aliás, impulsionou o desenvolvimento das ciências, do sentimento nacional e também do ponto de vista geral dos fatos humanos.

O tema da linguagem chega até Ferdinand de Saussure, mentor do pensamento estruturalista, com profundas reconsiderações sobre o estudo tradicional das línguas. $\mathrm{O}$ anseio por uma ciência linguística levou à rejeição as gramáticas lógico-filosóficas, sob a acusação de empregarem uma abordagem especulativa da linguagem e por não adotar o método dedutivo de análise. Por sua vez, as gramáticas históricas consideravam o aspecto evolutivo das línguas como o fator central do que seria a natureza da linguagem. Mas qual ponto de vista seria de fato a perspectiva mais satisfatória de uma ciência linguística?

Na obra póstuma Curso de Linguística Geral, publicada em 1916, Saussure pontuou que o fenômeno linguístico, comportamento verbal de expressão e compartilhamento de ideias por meio de signos linguísticos, requer antes de tudo um estudo autônomo capaz de oferecer integralmente o objeto de estudo da Linguística, isto é, observar a língua sob uma perspectiva linguística bem delimitada, livre de "um aglomerado confuso de coisas heteróclitas, sem liame entre si" (SAUSSURE, 2003, p. 16). A princípio, a tese saussuriana tinha co- 
mo alvo imediato o método indutivo-inatista da Gramática Tradicional, mas a suas críticas também ecoaram para os neogramáticos.

Saussure estava atento ao fenômeno linguístico como comportamento social. Para tanto, ele estabelece uma investigação de forma a atribuir à linguagem seu lugar no universo dos fatos humanos, provando-a não ser apenas um produto do acaso ou de uma evolução, mas um sistema bem estabelecido na contemporaneidade.

Primeiramente, o estruturalista atenta para o fato de o fenômeno linguístico ser observado por diferentes pontos de vista que se distinguem sempre em séries dicotômicas. Dentre elas, destacamos duas:

A linguagem tem um lado individual e um lado social, sendo impossível conceber um sem o outro. (...)

A cada instante, a linguagem implica ao mesmo tempo um sistema estabelecido e uma evolução: a cada instante, ela é uma instituição atual e um produto do passado. (SAUSSURE, 2003, p. 16)

Chamam atenção os lados social e sincrônico da linguagem, até então não contemplados juntamente pelos estudos em vigor. Saussure constatou a partir desses dois pontos uma interseção que pudesse ser de fato o real objeto de estudo da Linguística. Para tanto, ele definiu a língua como esse objeto científico tido como imprescindível para o estudo teórico e que pudesse explicar, ao mesmo tempo, a natureza do fenômeno linguístico. Sendo assim, a língua não pode ser individual - responsável apenas pela execução da fala nem fundamentalmente histórico - pois é socialmente em um tempo e em um espaço determinados que ela é adquirida e estabelecida por completo.

No entanto, o que determinaria à língua o se caráter social homogêneo? Mais uma vez, Saussure vê na coletividade a resposta para essa condição: a língua é um sistema; um sistema de signos linguísticos arbitrários, o que prova ser uma convenção totalmente social. Sendo, portanto, uma convenção social,

É, ao mesmo tempo, um produto social da faculdade de linguagem e um conjunto de convenções necessárias, adotadas pelo corpo social para permitir o exercício dessa faculdade nos indivíduos. (...)

A língua (...) é um todo por si e um princípio de classificação. (SAUSSURE, 2003, p. 17). 
Antes de ser um sistema linguístico, a língua é um conjunto de códigos sociais culturais que estão dispostos numa sincronia. Saussure procura ir mais além ao se interessar pela infraestrutura da língua, aquilo que é comum a todos os falantes e que está fora do domínio individual. Uma vez classificável entre os fatos humanos, a língua é um sistema de regras e convenções que permite a si própria de operar. Esse detalhe permite constatar que as convenções sociais são subordinadas a um fenômeno social maior que "legisla" as instituições coletivas, sendo a língua uma parte específica dos fatos humanos - um sistema de signos que exprimem ideias. Para tanto, seria necessária

uma ciência que estude a vida dos signos no seio da vida social, (...) A Linguística não é senão uma parte dessa ciência geral; as leis que a Semiologia descobrir serão aplicáveis à Linguística e esta se achará dessarte vinculada a um domínio bem definido no conjunto dos fatos humanos. (SAUSSURE, 2003, p. 24)

Saussure conclui a sua investigação do objeto linguístico e sua natureza ao atentar para a necessidade de se tomar a língua "em si mesma" a fim de distingui-la das outras instituições humanas; os signos são diversos, mas os linguísticos são arbitrários e estruturados para articular e expressar ideias. Essa disposição à observação do geral para o específico, isto é, dos conjuntos dos fatos humanos para a língua como competência individual, levou a própria Linguística estruturalista a ser criticada por desconsiderar a importância das pessoas na complexa rede das relações sociais, bem como fatores individuais e sociais dinâmicos que têm implicação direta e indireta na linguagem humana.

\subsection{O radicalismo de Bloomfield}

Durante a primeira metade do século XX, um forte pensamento começou a indagar a natureza epistemológica das ciências. Os estudiosos positivistas conceberam a ideia do reducionismo, isto é, a certeza de que uma ciência mais básica poderia ser reduzida a outra mais específica. A generalização reducionista concebeu o método científico de investigação aplicável a todos os ramos da ciência, baseadas na observação de dados coletados empiricamente. 
Com o abandono do racionalismo, a Linguística, de fato, passou a ostentar um caráter científico. Mas foi com Bloomfield que o ideal de ciência se tornou mais perseguido. $\mathrm{O}$ teórico, recebendo forte influência dos psicólogos behavioristas, admite que

\begin{abstract}
tudo que é descrito como um produto da mente humana, incluindo a língua, pode ser descrito satisfatoriamente pelo reforço e condicionamento dos reflexos puramente fisiológicos e, em último termo, por hábitos de estímulo-resposta. (LYONS, 1987)
\end{abstract}

Com Bloomfield, o descritivismo estava em voga. A tese da relatividade linguística foi aceita no seu grau mais latente para defender a natureza de todas as línguas humanas a partir de suas respectivas propriedades estruturais. Uma das versões da teoria do estímulo-resposta foi aplicada à aquisição e ao uso da linguagem. Segundo a psicologia experimental, a aquisição se dá na fase infantil por condicionamento e pela imitação da fala adulta. Sem a interação social, por exemplo, seria impossível ao ser humano adquirir a linguagem. O uso, por sua vez, poderia ser descrito como comportamento previsível na presença de determinados estímulos oferecidos pelo ambiente que remetessem a experiências anteriormente vividas. Bloomfield desvinculou totalmente a mente da linguagem, sendo esta um conjunto de estímulos semióticos que remeteriam a respostas possivelmente antevistas.

O descritivismo bloomfieldiano e pós-bloomfieldiano (e a consequente subordinação à psicologia behaviorista) contribui consideravelmente para a compreensão científica geral da Linguística e, sem dúvida, isso só tornou possível por ter se tornado mais empírica e objetiva do que especulativa.

\title{
2.5. Os funcionalistas
}

A princípio, convém denominar funcionalismo o movimento linguístico que principiou com os trabalhos do Círculo Linguístico de Praga, em 1926, quando se apresentou como um ramo particular do estruturalismo, fortemente influente na linguística europeia. A partir deste marco, diversos estudos se identificaram com o movimento, tornando-o um campo teórico com dimensões bastante abrangentes. 
Um dos importantes impulsos para o funcionalismo foi exatamente o contraste a alguns pontos da teoria saussuriana, tais como a refutação à distinção entre sincronia e diacronia e a concepção de homogeneidade do sistema linguístico. Possuindo intensa interdisciplinaridade com a antropologia e a sociologia, os integrantes da Escola de Praga associaram as estruturas gramatical, semântica e também fonológica dos sistemas linguísticos às funções sociais que desempenham em cada cultura. As investigações, portanto, transcenderam o limite da formalização gramatical e debruçou-se na análise de todos os fenômenos influentes no evento da fala e de que forma esses fenômenos determinavam a estrutura e a regularidade do discurso. Neste ponto, o funcionalismo dá maior consideração à fala em relação ao estruturalismo, não a desvinculando da língua.

Mas foi na fonologia que o funcionalismo europeu apresentou as inovações teóricas. Até então, os fonemas eram analisados do ponto de vista concreto como unidades da fala, passando a ser considerados no gênero abstrato das línguas, cujas relações opositivas eram determinantes no significado das unidades do discurso, tanto no nível segmental quanto no nível suprassegmental. Dessa Escola, destacam-se os trabalhos de Nicolaj Trubetzkoy e Roman Jakobson.

A noção de traços distintivos, apresentados por Trubetzkoy, ajudou a distinguir definitivamente fonética de fonologia. $\mathrm{O}$ fonema seria o conjunto abstrato de traços distintivos simultâneos, capazes de estabelecer oposição de significados. Desta forma, os traços distintivos também são incorporados à estrutura linguística, que determinam os sons da língua. Além das funções distintivas das unidades mínimas do sistema linguístico, Trubetzkoy desenvolveu o quadro das funções demarcadora e expressiva dos fonemas na cadeia sonora. $\mathrm{Na}$ função demarcadora, a prosódia demarca a fronteira significativa entre cadeias sonoras semelhantes. Na função expressiva, os traços distintivos refletem as condições psíquicas do falante, bem como as motivações pragmáticas e a competência discursiva. Já Jakobson, apresentou o conceito de categorias marcadas e não marcadas na morfologia.

Posteriormente, os estudos iniciados no Círculo Linguístico de Praga estenderam o campo da fonologia e se concentraram na 
descrição funcional das sentenças, especialmente nas motivações pragmáticas que determinariam a estrutura gramatical das línguas.

\subsection{Chomsky e a "gramática transformacional"}

Nas primeiras décadas do século XX, a Linguística ostentava condição teórica jamais contemplada em qualquer época passada. As descobertas realizadas a partir do estruturalismo de Saussure e do descritivismo de Bloomfield pareciam apresentar provas irrefutáveis sobre a natureza da linguagem e seu processo de aquisição. A convicção relativista das línguas e a tese do estímulo-resposta proporiam, no mínimo, que a aquisição linguística se dá por meio da interação social, regulada através de signos semióticos, ou signos linguísticos. Contudo, alguns destaques deveriam ser considerados: por que uma criança com média de dois anos de idade revela uma aquisição considerável, senão praticamente completa, da gramática de sua língua materna? Será que toda a sua fala é mera repetição da fala de alguns adultos, que fazem parte do seu meio social? Por que são comuns os erros de fala infantil voltados para a regularidade da língua? Outro ponto importante: como explicar o fato das pessoas produzirem instantaneamente frases inéditas e criativas gramaticalmente aceitas? Essas questões tiveram em Noam Chomsky seu principal formulador.

Na década de 1950, outro contexto delineava novas tendências que marcaram o século passado. A chamada revolução cognitiva reagiu contra a análise de estímulo-resposta e considerou o comportamento humano e seus produtos não como objeto de investigação restrita em si mesmo, mas como meio direcionado à descrição mental e seus mecanismos internos responsáveis pelos fatos humanos. A psicologia, por exemplo, sofreu grandes redefinições, deixando de se submeter às leis do behaviorismo. O próprio Chomsky teve interferência direta nessa atuação, definindo-a como ciência restrita à descrição do comportamento humano. Um dos argumentos utilizados foi a de que o behaviorismo extrapolou os limites da observação, conferindo à psicologia uma atribuição científica canônica, capaz de explicar tudo relativo ao ser humano por meio de uma única forma de análise. 
Mas foi em Linguística que Chomsky exerceu influência decisiva. Para ele, o prodígio de crianças em adquirir uma língua, mesmo muito novas, não se explica somente por fatores empíricos e/ou por processos de aprendizado demandados pela interação com adultos, mas evidencia uma faculdade da linguagem exclusivamente humana e primariamente inata da espécie. Segundo Chomsky, a habilidade em expressar os mais íntimos e espontâneos pensamentos a outro indivíduo por meio de signos linguísticos só pode e deve ser entendida como disposição pré-determinada da mente para o sistema linguístico.

$\mathrm{Na}$ psicologia behaviorista, a mente estava livre de consideração, ou porque ela não poderia ser observada experimentalmente ou porque seria um mero registro dos reflexos fisiológicos experimentados. $\mathrm{O}$ fato era que a análise de estímulo-resposta vigorava até então como base teórica do estudo científico da linguagem. Demais estudos, mais avançados, partiram de um fato muito simples: não é necessária a coincidência de condições ambientais para motivar a expressão de uma palavra ou frase. Em termos práticos: não é necessário presenciar um pássaro para se proferir a palavra "pássaro". Desta forma, a aquisição e o uso de uma língua passam a ser entendidos como independentes de estímulo. Essas primeiras conclusões podem ser arrematadas com o seguinte trecho:

Um olhar cuidadoso sobre a interpretação de expressões revela bem rapidamente que desde os primeiros estágios a criança sabe muito mais do que lhe foi fornecido pela experiência. Isto é uma verdade até mesmo para palavras simples. Nos momentos de pico do crescimento da língua, uma criança está adquirindo palavras numa velocidade aproximada de uma por hora, com exposição extremamente limitada e em condições grandemente ambíguas. As palavras são compreendidas de modo sutis e intricados que vão muito além do alcance de qualquer dicionário, e que estão apenas começando a ser investigados. (CHOMSKY, 1997)

Outra evidência importante foi observada em paralelo com a linguística estruturalista. A abordagem estrutural e a descrição distribucional e funcional das unidades do discurso, bem como a gramática de constituintes e a formulação de regras de estrutura sintagmática (Cf. AZEREDO, 2003, p. 23), primaram pela organização metódica das frases e da língua, revelando-se insuficientes para explicar dados de intuição não explícitos no enunciado ou admitir aproximações nocionais entre duas frases com construções lineares diferentes. Essa 
produtividade das frases, não contemplada pelo estruturalismo, não poderia ser explicada a partir de um modelo sintagmático da frase. Segundo Chomsky, a única explicação válida é que há uma relação análoga entre língua e mente, capaz de comprovar que há um módulo determinado que opera e gera frases de acordo com a demanda do pensamento.

Chomsky procurou dar conta dessa tese com a formulação teórica da gramática gerativa transformacional. Para ele, admite-se que um determinado modo de expressão só pode ser considerado uma língua quando obtiver a propriedade da recursividade, isto é, proporcionar condições de combinações infinitas capazes de produzir "enunciados potenciais" (LYONS, 1987) para expressar ideias livres a partir de uma quantidade limitada de sons (e letras). Retomando a abordagem mentalista tradicional, o teórico reconsidera uma intriga marcante entre os autores das gramáticas de Port-Royal: como é possível, a partir de um número limitado de sons, produzir uma quantidade ilimitada de expressões sobre qualquer coisa que pretendemos revelar? A explicação perpassa pelas diversas assunções da palavra língua.

A acepção de língua (langue) proposta por Saussure é observada em Chomsky como sistema linguístico, um universo onde se encontram todas as condições para a organização e produção de sentenças possíveis. Desta forma, sistema linguístico seria "um conjunto (finito ou infinito) de sentenças, cada uma finita em comprimento e construída a partir de um número finito de elementos". (LYONS, 1987)

Cada sistema de signos linguísticos é estruturado em níveis de combinações fonológicas e sintáticas. Essa estrutura, por sua vez, é abstrata, porque não possui existência física, e regular, pois é observada uma homogeneidade na atividade de interação humana. Somente a partir do comportamento linguístico estável de uma comunidade de falantes que se torna possível descrever a estrutura dos sistemas linguísticos.

Em tese, não haveria razão para uma estrutura abstrata tão complexa como são os sistemas linguísticos ser adquirida se estes não fossem um produto universal de natureza mental. Isto significa que, além das propriedades formais subjacentes, todas as línguas são 
originadas de uma matriz biológica comum. Prova disso é a capacidade relativamente precoce das crianças em gerar frases com considerável facilidade, apesar da inexperiência. Satisfeita essa condição metodológica, toda língua natural tem como exigência alocar-se no estado inicial pré-determinado da mente. Nesse caso, o comportamento linguístico também é meio de observação à descrição dos sistemas linguísticos segundo a estrutura mental e de seus mecanismos internos, uma vez que se busca adequar a linguagem como parte integrante do estudo da espécie.

A língua internalizada pelo falante ou o conhecimento intuitivo sobre uma língua natural é denominado gramática gerativa, pois permite que ele gere frases de acordo com sua criatividade, legislada, portanto, por regras de boa formação. A essa capacidade de se "gerar expressões infinitas por meios finitos", juntamente com a capacidade de se adotar determinado tipo de comportamento linguístico, correspondem à competência linguística do indivíduo.

Sendo assim, essas delimitações proporcionaram a Chomsky a elaboração de um primeiro modelo cognitivo de língua, com dois níveis de representação sintática: a estrutura profunda e a estrutura superficial. A primeira corresponde à proposição, o estado inicial abstrato para todas as frases possíveis de uma língua; a segunda corresponde aos enunciados concretos propriamente ditos.

Sem dúvida, as inovações de Chomsky causaram impactos marcantes no quadro da linguística geral: a) por resgatar a tradição racionalista, então refutada no advento do gerativismo; b) por redirecionar o estudo do sistema linguístico não apenas como caráter social, ou mais próximo à sociologia, como propunha Saussure, mas como ramo da psicologia cognitiva; c) por conceber a língua como independente de meio em que se manifesta, devido ao seu caráter abstrato; d) por estabelecer a independência entre si dos níveis da estrutura do sistema linguístico, de modo que a combinação dos elementos no nível fonológico não determina a estrutura do nível sintático, ou vice-versa. 


\section{A natureza da linguagem: confronto entre paradigmas}

Ao longo do tempo, os principais quadros teóricos relacionados ao estudo da linguagem se afirmaram essencialmente na substituição do movimento até então vigente. No entanto, as diversas abordagens apresentaram pontos de vista imprecisos ou passíveis de críticas, relativizando em muito o ensino e o estudo da linguagem.

Com o advento do gerativismo, as explicações sobre a natureza da linguagem se centralizaram no sistema linguístico como reflexo da estrutura cognitiva. A incorporação do comportamento linguístico determinava a linguagem como propriedade humana inata e privativa da espécie, admitindo haver um comportamento específico para a mesma que demandaria uma competência voltada para o conhecimento satisfatório das regras gramaticais que geram as frases de uma língua. A homogeneidade linguística é observada pelos cognitivistas como aspecto que comprova a prioridade da gramática como descrição dos mecanismos de funcionamento mental característicos da vida humana. A estruturação do sistema linguístico é, portanto, determinada por fatores internos da mente, universais e subjacentes a todas as línguas.

Essas questões foram contestadas pelo funcionalismo, que postula a relação da linguagem com o uso e com o contexto de sua realização. $\mathrm{O}$ caráter abstrato do sistema linguístico bem como a competência voltada exclusivamente para a capacidade de geração de sentenças são observados pelos funcionalistas como fatores secundários ao real objeto de estudo da linguística, que seriam as ações e os fenômenos concretos mediados e relacionados com a linguagem; sendo assim, o modelo funcionalista da linguagem não desconsidera a parte relativa ao desempenho.

Esse ponto de contraste motivou os próprios funcionalistas a distinguirem os dois quadros gerais de estudos linguísticos: o polo formalista e o polo funcionalista. O primeiro passaria a designar os estudos relacionados à forma das línguas, que não considerariam os aspectos socioculturais envolvidos na linguagem. Sob essa designação, seriam assim denominados o estruturalismo de Saussure, o descritivismo de Bloomfield e o gerativismo de Chomsky. Todos esses movimentos enxergariam na estrutura o objeto do estudo linguístico e ao modo de comportamento voltado para a gramática. Apesar das 
inúmeras distinções entre os integrantes do formalismo, o ponto de vista formal tornou-se o principal tema atribuído aos maiores expoentes dos respectivos grupos, enfatizando o perfil teórico latente que certamente os aproximam em determinado aspecto. As aproximações seriam: a) o estruturalismo e o gerativismo analisariam o caráter abstrato da língua como sistema linguístico, relegando o desempenho, a fala concreta propriamente dita, em favor da regularidade das relações entre os signos linguísticos; b) o estruturalismo e o descritivismo admitem que a natureza do signo linguístico arbitrário é exterior à cognição e que o comportamento coletivo é determinante para manter a natureza opositiva e contrastiva das partes do discurso; c) o descritivismo e o gerativismo estariam próximos por apreciar tanto o comportamento coletivo quanto o comportamento individual por meio da gramática. No entanto, até mesmo por razões cronológicas, o gerativismo tem sido apontado como o principal representante da corrente formalista, por manter uma rotina de estudos mais intensa e prolongada em relação aos outros dois.

Já o termo funcionalismo, permanente desde o Círculo Linguístico de Praga, designaria o estudo relativo das funções que a linguagem desempenha na realidade social, desde um simples código até mesmo a organização de uma gramática, sempre voltada para a finalidade comunicativa. De certa forma, o paradigma funcionalista caracteriza-se por contemplar um campo de observação muito mais amplo, uma vez que se propõe a analisar as situações concretas que entram em jogo na atuação linguística. A competência seria vista não mais como a aquisição ou a capacidade fluente da aplicação das regras gramaticais, mas como capacidade comunicativa, na interação proveitosa da língua com o contexto onde se está inserido. Esse domínio demanda, portanto, uma habilidade além da gramatical ou dos denominados "universais linguísticos" inatos; demanda um conhecimento pragmático da linguagem como ação de interação social.

Em contraposição, o argumento de Chomsky é válido para defender a perspectiva do formalismo. A habilidade em se expressar os mais íntimos e espontâneos pensamentos a outro indivíduo por meio de signos linguísticos não é proporcionada pelo aprendizado de um conjunto de fatos sociais estruturados em signos semióticos, capaz de armazenar todo o espírito da coletividade, mas sim a capacidade de expressão inata por meio de signos. Nesse ponto, por exemplo, não é 
difícil relacionar o estruturalismo com o funcionalismo, o que mostra a variabilidade das opiniões. No entanto, o formalismo sofreu reformulações, feitas pelo próprio Chomsky, impulsionadas inclusive pelos funcionalistas, como a inserção da fonologia como aspecto linguístico analítico e também a particularidade de cada sistema linguístico como meio de comunicação e interação. Porém, o que ainda se mantém é o argumento inatista, para explicar o processo de aquisição da linguagem a partir de um estado inicial geneticamente determinado (algo não tão bem contemplado pelo funcionalismo) e o argumento racionalista, para se justificar a relação análoga entre linguagem e mente.

Mas, de todas as divergências reveladas entre esses dois polos, o que parece ser o cerne da discussão é o modo como cada um enxerga a linguagem a partir do binômio forma $\rightarrow$ semântica. Segundo o formalismo, a estrutura sintática é o meio de construção do sentido das frases, o que coloca a sintaxe numa instância anterior à semântica. O que se busca comprovar é que não há veiculação de sentido se a sintaxe for desconsiderada. O programa de parsing apresentado no minimalismo chomskiano busca comprovar a inter-relação de diversos processos cognitivos voltados para o processamento e análise de sentenças. As partes do discurso seriam também meios de busca para a seleção de palavras no acervo cognitivo. Ostentando um perfil muito mais eclético, o funcionalismo foi assumido para se comprovar a supremacia da pragmática ante à forma, até mesmo para submeter a organização da língua por meio do uso. Todavia, parecendo ser um ramo do funcionalismo mais consistente, o programa sistêmico-funcional, proposto por Halliday, defende um perfil mais teórico dos estudos da linguagem. Segundo Halliday (1993), a língua pode ser estudada por diversos ângulos, sendo que a gramática é determinada pelas relações fonológicas e semânticas. A supremacia da semântica pôde ser exposta nas orientações das escolhas do sintagma preferido sempre diante de duas opões possíveis. Cada processo de escolha revela a ativação de certo sistema, o que determina um modelo de linguagem como sistema composto por vários sistemas. 


\section{Conclusão}

O presente texto é um ensaio geral das principais perspectivas linguísticas que influenciaram ou ainda sustentam boa influência na geração de pesquisadores ao longo dos anos até os dias presentes. $\mathrm{O}$ objetivo principal deste trabalho foi expor as principais correntes no intuito de contextualizá-las e confrontar os paradigmas presentes de estudo, bem como auxiliar pesquisadores iniciantes e estudantes de letras que pretendem ter uma compreensão atual no quadro da linguística geral.

Para tanto, a linguística foi analisada primeiramente sob um olhar histórico, na tentativa de se apresentar os diversos pontos de vista que figuraram desde o princípio da análise gramatical ainda na antiguidade e de compor um quadro abrangente da evolução das ciências da língua. Porém, todo esse recurso visava atingir com muito mais referências a dinâmica das discussões promovidas pelos polos formalista e funcionalista neste início de século. Intentou-se, também, explicar os motivos para o advento do funcionalismo e as razões para a alcunha do termo formalismo, que reuniria assim o estruturalismo, o descritivismo e o gerativismo em um mesmo grupo.

Todavia, alguns pontos não foram devidamente aprofundados e que poderiam perfeitamente tornar a leitura mais expansiva e esclarecedora. Tais questões como o detalhamento das mudanças de paradigmas, que não foram exaustivamente contemplados nesse texto, poderiam apresentar uma noção mais acurada sobre o impacto que cada movimento teórico exerceu em cada época. Outra questão importante é, apesar das divergências de perspectivas, de que forma o paradigma formalista e o paradigma funcionalista poderiam se complementar e proporcionar um ponto de partida mais tranquilo nos estudos da linguística. Consequentemente, fica em aberto uma abordagem mais embasada sobre o binômio forma $\rightarrow$ semântica para se questionar com mais propriedade a tese da anterioridade da sintaxe em relação à semântica e vice-versa. E por fim, faltou inserir com devida justiça as contribuições atuais da sociolinguística. Assunto que trataremos mais adiante em texto separado.

Fica, portanto, como proposta dessa leitura a possibilidade de se iniciar a análise dos principais paradigmas que podem esclarecer o professor na atividade de ensino da língua materna em sala de aula, 


\section{FACULDADE de FoRMAÇÃO de PROFESSORES}

como também proporcionar uma visão mais crítica da linguagem e das publicações literárias a seu respeito.

\section{BIBLIOGRAFIA}

AZEREDO, J. C. Iniciação à sintaxe do português. Rio de Janeiro, JZE, 2003.

CALLOU, D. \& LEITE, Y. Iniciação à fonética e à fonologia. 9. ed. [Rio de Janeiro]: J. Zahar, [2003].

CHOMSKY, N. Novos horizontes no estudo da linguagem. DELTA v. 13, nº especial. São Paulo, 1997.

LYONS, J. Lingua(gem) e linguística. Rio de Janeiro: LTC, 1987.

MARTELOTTA, M. (Org.). Manual de linguística. [São Paulo]: Contexto, [2008].

MENDONÇA, M. C. Língua e ensino: políticas de fechamento. In.: MUSSALIM, F. \& BENTES, A. C. (Org.). Introdução à linguística: domínios e fronteiras. V.2. São Paulo: Cortez, 2001.

MILLER. G. A. The cognitive revolution: a historical perspective. In.: Trends in Cognitive Sciences. Vol. 7, No 3, March 2003.

SAUSSURE, F. Curso de linguística geral. São Paulo: Cultrix, 2003. 